\title{
NISTIR 6262
}

\section{Program Handbook}

\section{Accreditation \\ Requirements for Quality \\ System Registrars Under \\ Provisions of the Fastener \\ Quality Act}

\section{S. Wayne Stiefel}

Robert L. Gladhill

Office of Standards Services

Technology Services

QC

100

.456

N0.6262 

NISTIR 6262

\section{Program Handbook}

\section{Accreditation \\ Requirements for Quality \\ System Registrars Under \\ Provisions of the Fastener \\ Quality Act}

\section{S. Wayne Stiefel}

Robert L. Gladhill

Office of Standards Services

Technology Services

December 1998

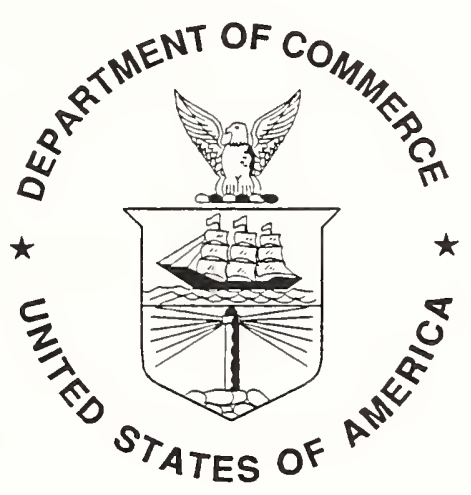

U. S. DEPARTMENT OF COMMERCE

William M. Daley, Secretary

TECHNOLOGY ADMINISTRATION

Gary R. Bachula, Acting Under Secretary for Technology

NATIONAL INSTITUTE OF STANDARDS AND TECHNOLOGY

Raymond G. Kammer, Director 



\section{ACKNOWLEDGMENTS}

The authors would like to acknowledge the assistance of Jogindar S. Dhillon of the Office of Standards Services for researching the regulations as they pertained to accreditation of registration bodies and registration of facilities. Special thanks are also due to Gerry Funk for her patience in reworking the manuscript through many drafts, and production of a wellformatted handbook. 



\section{TABLE OF CONTENTS}

Section

Page

1.0 INTRODUCTION 1

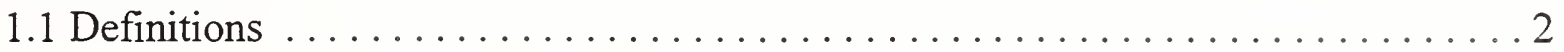

2.0 REQUESTING EVALUATION $\ldots \ldots \ldots \ldots \ldots \ldots \ldots \ldots \ldots \ldots \ldots \ldots \ldots \ldots \ldots$

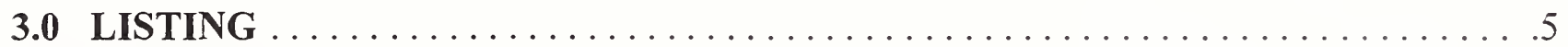

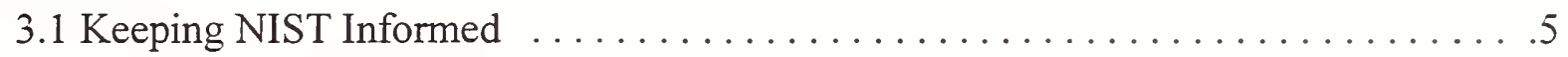

3.1.1 Accredited Registrar Status . . . . . . . . . . . . . . . . . . .5

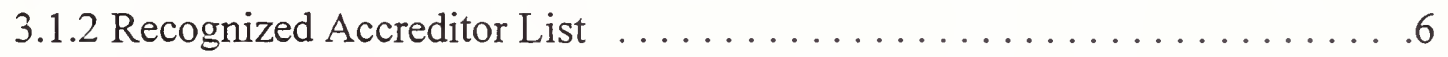

3.1.3 List of Facilities . . . . . . . . . . . . . . . . . . . 6

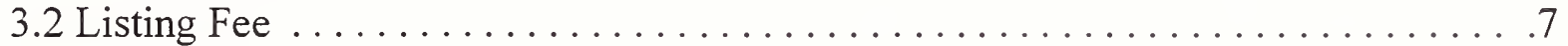

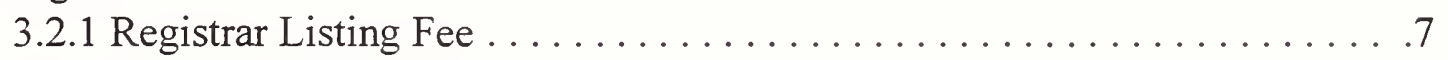

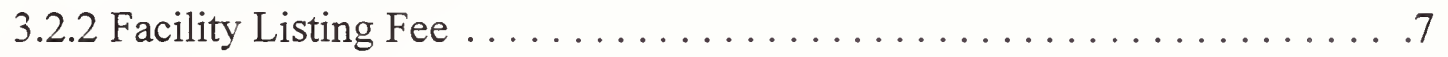

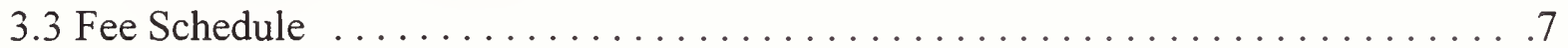

4.0 REPORTS AND RECORDKEEPING $\ldots \ldots \ldots \ldots \ldots \ldots \ldots \ldots \ldots \ldots$

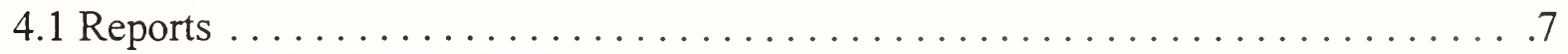

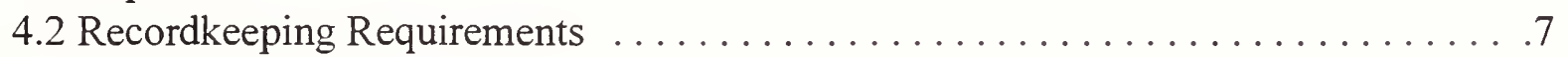

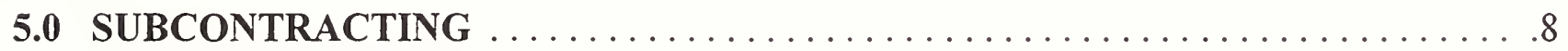

6.0 MAINTAINING RECOGNIZED STATUS $\ldots \ldots \ldots \ldots \ldots \ldots \ldots \ldots \ldots \ldots$

6.1 NIST Surveillance/Observer Status . . . . . . . . . . . . . . . . . 10

6.2 Proper Use of Accredited Status and Claims . . . . . . . . . . . . . . 10

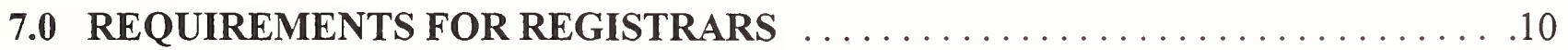

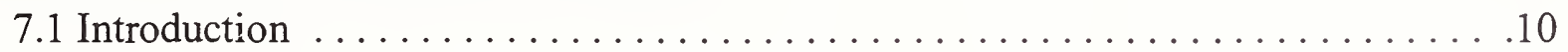

7.2 Requirements for Registrars (From Subpart L of the Regulations) . . . . . . . . . 11

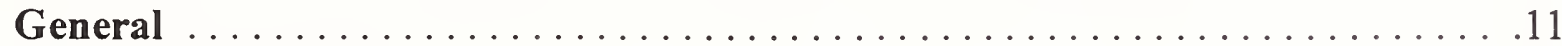

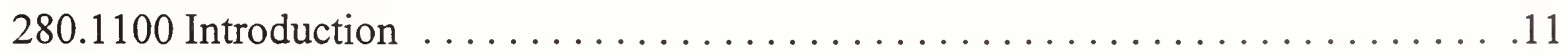

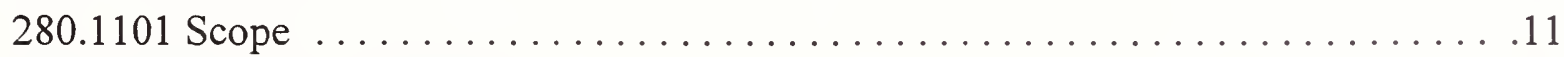

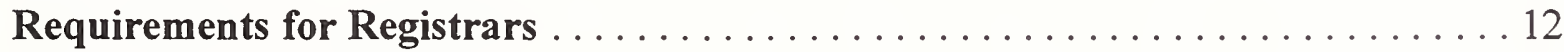

280.1110 Registrars . . . . . . . . . . . . . . . . . . . . . . 12

280.1111 Registrar Personnel . . . . . . . . . . . . . . . . . . 21

280.1112 Changes in the Registration Requirements . . . . . . . . . . . . . . 24

280.1113 Appeals, Complaints and Disputes . . . . . . . . . . . . . . . 24

Requirements for Registration . . . . . . . . . . . . . . . . . 24

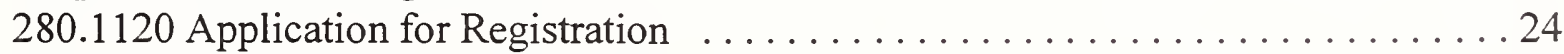

280.1121 Preparation for Assessment . . . . . . . . . . . . . . . . . . . 26

280.1122 Assessment . . . . . . . . . . . . . . . . . . . . . . . . 27 
280.1123 Assessment Report . . . . . . . . . . . . . . . . . . . . . . . 27

280.1124 Decision on Registration . . . . . . . . . . . . . . . . . . 28

280.1125 Surveillance and Reassessment Procedures ................... . . 29

280.1126 Use of Certificates and Logos . . . . . . . . . . . . . . . . 30

280.1127 Access to Records of Complaints to Fastener Manufacturers . . . . . . . . 30

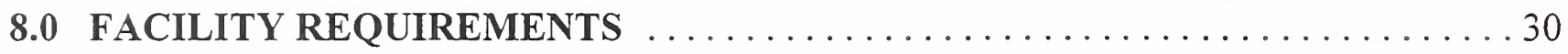

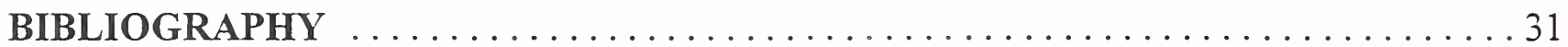




\subsection{INTRODUCTION}

On November 16, 1990, the United States Congress enacted the Fastener Quality Act (FQA), P.L. 101-592 (the Act). The Act was amended in 1996 by Section 11 of P.L. 104-113. The Act protects the public safety by: (1) requiring that certain fasteners which are sold in commerce conform to the specifications to which they are represented to be manufactured; (2) providing for accreditation of laboratories engaged in fastener testing and registration of manufacturing facilities; and (3) requiring inspection, testing and certification, in accordance with standardized methods, of fasteners covered by the Act.

This handbook describes the NIST requirements that Registrars ${ }^{1}$ of Quality Systems seeking accreditation to register fastener manufacturers, employing a fastener quality assurance system (QAS), must satisfy. It provides specific guidance on the implementing regulations (the Regulations) published at 15 CFR Part 280 "Procedures for Implementation of the Fastener Quality Act", Subparts I through L. ${ }^{2}$

This handbook amplifies subpart L of the Regulations, which is based on ISO/IEC Guide 62, and complements other handbooks in the QAS series. NISTIR 6261, which is based on ISO/IEC Guide 61, provides guidance to Accreditors desiring NIST recognition for meeting the requirements of subpart $\mathrm{K}$ of the regulation. NISTIR 6263 provides guidance to Facilities to satisfy the elements of a fastener QAS and contains the audit requirements for Registrars to register facilities.

Selected text from the regulations is presented in italics in some sections of this handbook. For full understanding of all requirements, interested parties are advised to read the Regulations in their entirety. In addition to the quality system registration requirements, many other important issues are contained in that document. The Act and Regulations are accessible on the NIST FQA Home Page (http://www.nist.gov/fqa).

NIST invites users to provide comments or suggestions for modifications, clarification or improvement of this document. Comments should be addressed to Accreditation Body Evaluation Program (ABEP) Program Manager, NIST, 100 Bureau Drive, Stop 2100, Gaithersburg, MD 20899-2100.

\footnotetext{
${ }^{1}$ Note: In some countries, the bodies which verify conformity of quality systems to specified standards are called "certification bodies," in others "registration bodies," in others "assessment and registration bodies" or "certification/registration bodies," and in still others "registrars." Reference to such bodies as "Registrars" should not be understood to be limiting. CFR Part 280.

${ }^{2}$ Section numbers denoted by "Sec." or "Sec. 280.xxx" in this document reference the regulations at 15
} 


\subsection{Definitions}

For the purposes of this handbook, the following definitions are used. Those definitions taken from The Act or regulations are shown in italics.

1.1.1 Accreditation: A Procedure by which a body recognized by NIST confirms that a testing laboratory or a quality system registrar of fastener manufacturing facilities that employ a Fastener Quality Assurance System is competent to carry out specific tasks required by the implementing regulations for the Fastener Quality Act.

1.1.2 Accreditation Body Evaluation Program (ABEP): The program established by NIST to receive applications and to evaluate Accreditors (of testing laboratories or of quality system registrars) to determine if applicants meet applicable requirements of the Act and regulations at 15 CFR Part 280. Based on the evaluation results, $\mathrm{ABEP}$ makes recommendations to NIST regarding recognition of Accreditors.

1.1.3 Accredited Laboratory List: A list compiled and maintained by NIST of all testing laboratories which have been accredited either by NIST or by any NISTrecognized Accreditation Body in accordance with the requirements of The Act and the regulations.

1.1.4 Accredited Registrar: A quality systems registration body which is accredited by a NIST recognized Accreditor and appears on the Registrars List.

1.1.5 Accreditor: A Registrar accreditation body or testing laboratory accreditation body that is recognized by NIST, and appears on the Accreditors List.

1.1.6 Accreditors List: A list of all Accreditors that have been evaluated and recognized by NIST in accordance with the requirements of the Act. Two Accreditors Lists are maintained, one for testing laboratory accreditors and one for Registrar accreditors.

1.1.7 Act: The Fastener Quality Act, P.L. 101-592, as amended by P.L. 104-113.

1.1.8 Advanced Product Quality Planning: A structured process for developing and implementing the methods of measurement and testing that will be used in production of a specific product or family of products to meet requirements. Quality planning incorporates both defect prevention and continuous improvement, rather than defect detection. Proper implementation requires use of interdisciplinary teams and systems to assure management of appropriate activities (e.g., product design and development; development/finalization of special characteristics; product and process validation; development and review of Control Plans; mistake proofing; feedback, assessment and corrective action - 
continuous improvement) during concept development through production. (See, for example, Advanced Product Quality Planning and Control Plan QS-9000 reference manual.)

1.1.9 Approved Signatory: An individual employed by a facility registered under the Act and these regulations who is recognized by a registrar as competent to sign test reports.

1.1.10 Authorized Representative: An employee of an organization with the authority to make binding commitments on behalf of the organization. The authorized representative is the person who will be responsible for all communications between the Registrar and the Accreditor or NIST and who will ensure that the Registrar complies with all Accreditor and NIST program requirements.

1.1.11 Certificate of Registration: A document issued by a Registrar to a Facility that has met the criteria and conditions of registration. The certificate, together with the assigned code number and scope of registration issued by the Registrar, may be used as proof of registration status.

1.1.12 Control Plans: Plans that describe the system controlling fastener products and processes. They are written documents used by facilities to address the important characteristics and engineering requirements of the fastener product. Each fastener product shall have a Control Plan, but in many cases, "family" Control Plans can cover a number of fastener products produced using a common process. The control plan must be maintained throughout the fastener life cycle. Initially, it is primarily used to document and communicate the plan for process control. Later, it guides manufacturing in how to control the process and ensure fastener quality. Finally, the control plan is continually updated as measurement systems and control methods are evaluated and improved to reflect the current methods of control and measurement systems used in production. (See, for example, Advanced Product Quality Planning and Control Plan QS-9000 reference manual.)

1.1.13 Facilities List: A list compiled and maintained by NIST of all Facilities which have been registered by accredited Registrars.

1.1.14 Facility: A fastener manufacturing facility or a facility performing subcontracted processes for a manufacturing facility, that has been registered by an accredited Registrar and that appears on the Facilities List.

1.1.15 Fastener: Fastener means any screw, nut, bolt or stud, washer or other item included within the definition for fastener contained in section 3(5) of the Fastener Quality Act. The term "fastener" does not include a screw, nut, bolt or stud:

(1) that is produced and marked as ASTM A307 Grade A, 
(2) that is produced in accordance with ASTM F432: or

(3) that is held out as being produced to other than the provisions of standards and specifications published by a consensus standards organization, or a government agency.

A screw, nut, bolt, stud or washer held out as being produced according to requirements of a document other than a document published by a consensus standards organization is a fastener within the meaning of the Act and this part if that document incorporates or references (directly or indirectly) standards and specifications published by a consensus standards organization or government agency for purposes of delineating performance or materials characteristics of the fastener.

1.1.16 Fastener Quality Assurance System (QAS): (1) Fastener Quality Assurance System (QAS) means a fastener manufacturing system that has as a stated goal the prevention of defects through continuous improvement, and which seeks to attain that goal by incorporating: (i) Advanced product quality planning; (ii) Monitoring and control of the manufacturing process; (iii) Product verification activities embodied in a comprehensive and written control plan to address critical or significant product/process characteristics, documented process controls (including statistical process control), tests, and measurement systems to be used in production; and (iv) The creation, maintenance, and retention of electronic, photographic, or paper records, available for inspection during the periods required by section 10 of the Act and Sec. 280.809 of the regulations, regarding the inspections, tests, and measurements required by or performed pursuant to the control plan or other quality system documentation, e.g., work instructions. See Section 4.0, Fastener Quality Assurance System Criteria, for amplification of requirements.

1.1.17 Lot: A quantity of fasteners of one part number fabricated by the same production process from the same coil or heat number of metal as provided by the metal manufacturer and submitted for inspection and testing at one time.

1.1.18 Lot Number: A number assigned by a manufacturer to the lot.

1.1.19 Lot Traceability: The recording and maintenance of lot-specific identification information sufficient to trace fasteners from a single lot throughout:

(1) The manufacturer's fabrication or alteration process,

(2) All inspection and testing operations, and

(3) The subsequent chain of distribution in commerce.

1.1.20 Original Laboratory Testing Reports: (1) In general, a laboratory testing report which is originally signed by an approved signatory or is a copy thereof, certified by the laboratory that conducted the test; or (2) For purposes of the alternative procedures for chemical characteristics described in section 5 (d) of 
the Act and Sec. 280.15 of the regulations only, a laboratory testing report which is originally signed by an approved signatory or is a copy thereof, certified by the laboratory that conducted the test or by the metal manufacturer.

1.1.21 Recognized Accreditor: An accreditor that is recognized by NIST and appears on the Accreditors List.

1.1.22 Registered Facility: A facility that is registered by an accredited registrar and appears on the Facilities List.

1.1.23 Registrars List: A list compiled and maintained by NIST of all registrars who have been accredited by NIST-recognized Accreditors.

1.1.24 Registration: A procedure by which a body accredited by a NIST recognized Accreditor gives written assurance that a manufacturing facility conforms to the applicable requirements of a Fastener Quality Assurance System.

1.1.25 Tamper-resistant system: The use of special paper or embossing stamps or other controls which discourage, prevent or minimize alteration of test reports subsequent to manufacturing, inspection and testing.

1.1.26 Traceability of Measurements: A documented unbroken chain of comparisons all having stated uncertainties connecting the accuracy of a measuring instrument to other measuring instruments of higher accuracy and, ultimately, to a primary standard.

\subsection{REQUESTING EVALUATION - WHO MAY APPLY}

Registrars that consider they can comply with the requirements of the Act and regulations may apply to a NIST Recognized Accreditor for accreditation to perform registration of fastener Facility Quality Assurance Systems under the Fastener Quality Act.

\subsection{LISTING}

\subsection{Keeping NIST Informed}

3.1.1 Accredited Registrar Status: NIST will maintain lists of all Registrars that have been accredited by any Accreditors that are recognized by NIST. Only those Registrars on the Registrars List are legally eligible to register Facilities which can operate under the Act and implementing regulations.

Each Recognized Accreditor must keep NIST informed of all FQA Registrar accreditation actions. This information is vital for maintaining an current Registrars List. All new accreditations, renewals, denials, terminations, revocations, 
suspensions, and changes in scope (additions or deletions), must be reported to NIST within seven days, in English, by the recognized Accreditor.

Accredited Registrars should note that they cannot register Facilities to meet the requirements of the Fastener Quality Act regulations before the date their name appears on the Registrars List, and only the Recognized Accreditor may notify NIST of the accreditation action.

The notification of accreditation status by the Recognized Accreditor must include the following elements of information:

1. Name of Recognized Accreditor

2. Name of Accredited Registrar

3. Address of Registrar (Country, state, city, postal code)

4. Copy of Accreditation Certificate

5. Name of Registrar's Authorized Representative and telephone/Fax numbers

6. Nature of the accreditation action (e.g., initial, renewal, change in scope, etc.)

7. Scope of accreditation/change and effective dates

3.1.2 Accreditors List: NIST will maintain a list of the names and pertinent information on all Recognized Accreditors. Only listed Accreditors may accredit Registrars to register Facilities under The Act and implementing regulations. A Recognized Accreditor must remain in compliance with all conditions and requirements to retain its listing.

3.1.3 List of Facilities. NIST will prepare and maintain a list of Registered Facilities in accordance with Sec. 280.810(b).

(1) Names and information regarding Registered Facilities will be included on the list based on information submitted to NIST only by an accredited Registrar, who submits the listing fee established by NIST along with the following information:

(i) the name of Registered Facility and address of site location(s);

(ii) the name, title, address, telephone and fax numbers of the authorized representative of the Registered Facility;

(iii) the scope of registration, stating the fasteners and the quality system standard(s) to which the Registered Facility has been registered; and

(iv) the effective dates of the registration.

(v) fastener products included in QAS with a description of the fasteners covered by the Law and regulations and produced under the registered quality system(s) at the Registered Facility. 
(2) All Registrars listed by NIST in accordance with section 280.810 (b) shall promptly notify NIST of each registration action. Registration actions include initial registrations, renewals, suspensions, terminations, and changes in scope. All information must be submitted in the NIST specified format. Notifications shall be filed with: Fastener Quality Act Program Manager, Office of Standards Services, 100 Bureau Drive, Stop 2100, National Institute of Standards and Technology, Gaithersburg, Maryland 20899-2001.

The Accreditors List, the Registrars List and the Facilities List will be maintained on an electronic database, and entries will be updated as information becomes available on the NIST FQA Home Page (http://www.nist.gov/fqa).

\subsection{Listing Fee}

3.2.1 Registrar Listing Fee: The Registrar listing fee is paid by the Registrar and forwarded to NIST by a Recognized Accreditor.

3.2.2 Facility Listing Fee: The Facility listing fee is paid by the Registered Facility and forwarded to NIST by an accredited Registrar.

\subsection{Fee Schedule}

An ABEP Fee Schedule is published by NIST. Fees are subject to change at NIST's discretion. A new fee schedule will be provided to all participants whenever fees are changed.

\subsection{REPORTS AND RECORDKEEPING}

\subsection{Reports}

Accredited Registrars shall conform with the requirements of Sec. 280.808 of the regulations.

\section{Sec. 280.808 Reports.}

Reports and records shall be maintained in such a manner to preserve original data, and be collected as required into a final form, sufficient to satisfy customer and legal requirements. Such reports shall be provided upon request to the Bureau of Export Administration, to the National Institute of Standards and Technology, or to any other agency of the federal government authorized to obtain such records under this part.

\subsection{Recordkeeping Requirements}

Recognized Accreditors, Accredited Registrars and Registered Facilities shall conform with the requirements of Sec. 280.809 and Sec. 280.7 of the regulations. 


\section{Sec. 280.809 Recordkeeping.}

Each Recognized Accreditor, Accredited Registrar, or fastener manufacturer whose Facility has been registered shall retain all applicable records required under the Act and this part for 5 years. All records are subject to the requirements in Sec. 280.7 of this part.

\subsection{SUBCONTRACTING}

If an Accredited Registrar subcontracts any work, the subcontractor shall conform to Sec. 280.807 of the regulations. In addition, the quality documentation of an Accredited Registrar shall include procedures for subcontracting even if subcontracting is not a normal practice.

\section{Sec. 280.807 Subcontracting.}

If a Recognized Accreditor, an Accredited Registrar, or a Registered Facility subcontracts any of its functions to another entity it must place the work with another recognized Accreditor, Accredited Registrar, or Registered Facility; inform the client, before the fact, that subcontracting will be necessary, and clearly indicate in all appropriate records and reports to the client specifically what functions were subcontracted.

\section{Sec. 280.7 Recordkeeping Requirement}

(a) Each laboratory accredited under Subparts C, D, or E or Facility registered under Sec.280.104 of this part shall retain for 5 years after the performance of a test all records pertaining to that test concerning the inspection and testing, and certification, of fasteners under the Act and this part. The final test report or the test records maintained by the laboratory shall contain sufficient information to permit the test to be repeated at a later time if a retest is necessary. The laboratory shall maintain the test report and a record of all original observations, calculations, and derived data. The records shall include the identity of personnel performing the testing. Procedures for storage and retrieval of records must be documented and maintained in the laboratory's quality manual.

(b) Manufacturers, importers, private label distributors, and persons ${ }^{1}$ who significantly alter fasteners shall retain for 5 years after the performance of a test all records pertaining to that test concerning the inspection and testing, and certification, of fasteners under the Act and these regulations.

${ }^{1}$ The Regulations define Persons as any individual, partnership, limited partnership or corporate entity and/or a representative, agent or designee. 
(c) Original records required. Persons required to keep records under this part must maintain the original records in the form in which that person receives or creates them unless that person meets all of the conditions of paragraph (d) of this section relating to reproduction of records. Original laboratory test reports described in sections 280.5, 280.6, 280.13, and 280.15(b) of this part must be kept.

(d) Reproduction of original records. A person required to keep records under this part may maintain reproductions of documents other than laboratory test reports instead of the original records using any photographic, photostatic, miniature photographic, micrographic, automated archival storage, or other process that completely, accurately, legibly and durably reproduces the original records (whether on paper, microfilm, or through electronic digital storage techniques). The process must meet all of the requirements of paragraphs (d)(1) through (d)(9) of this section.

(1) The system must be capable of reproducing all records on paper.

(2) The system must record and be able to reproduce all marks, information, and other characteristics of the original record, including both obverse and reverse sides of paper documents in legible form.

(3) When displayed on a viewer, monitor, or reproduced on paper, the records must exhibit a high degree of legibility and readability. (For purposes of this section, legible and legibility mean the quality of a letter or numeral that enable the observer to identify it positively and quickly to the exclusion of all other letters or numerals. Readable and readability mean the quality of a group of letters or numerals being recognized as complete words or numbers.)

(4) The system must preserve the initial image (including both obverse and reverse sides of paper documents) and record all changes, who made them and when they were made. This information must be stored in such a manner that none of it may be altered once it is initially recorded.

(5) The regulated person must establish written procedures to identify the individuals who are responsible for the operation, use and maintenance of the system.

(6) The regulated person must establish written procedures for inspection and quality assurance of records in the system and document the implementation of those procedures.

(7) The system must be complete and contain all records required to be kept by this part or the regulated person must provide a method for correlating, identifying and locating records relating to the same transaction(s) that are kept in other record keeping systems.

(8) The regulated person must keep a record of where, when, by whom, and on what equipment the records and other information were entered into the system. 
(9) Upon request by the Bureau of Export Administration or NIST, the regulated person must furnish, at the examination site, the records, the equipment and, if necessary, knowledgeable personnel for locating, reading, and reproducing any record in the system.

(e) Destruction or disposal of records. If the Bureau of Export Administration, NIST or any other government agency makes a formal or informal request for any record or records, such record or records may not be destroyed or disposed of without the written authorization of the agency concerned. This prohibition applies even if such records have been retained for a period of time exceeding that required by paragraph (a) or (b) of this section.

(f) All persons required to keep records by this part must furnish those records when requested to do so by an employee of the Bureau of Export Administration or NIST.

\subsection{MAINTAINING RECOGNIZED STATUS (Sec 280.804)}

\subsection{NIST Surveillance/Observer Status}

NIST may, at its discretion, whether or not for cause, conduct a full or partial on-site visit or other forms of surveillance of any accredited Registrar or any of its Registered Facilities to observe or verify conformance with program requirements.

\subsection{Proper Use of Accredited Status and Claims}

Neither a Registrar accredited under the Act, nor any registered Facility shall take any action which constitutes or implies certification, approval, or endorsement by NIST or any other agency of the U.S. Government, of fasteners entered into commerce in the United States.

Neither an Accredited Registrar, nor any Registered Facility shall take any action which constitutes or implies that the Registrar, or Registered Facility is recognized by NIST for any activities beyond those specified in the NIST documents.

\subsection{REQUIREMENTS FOR REGISTRARS}

\subsection{Introduction}

These requirements, based on ISO/IEC Guide 62 - General requirements for bodies operating assessment and certification/registration of quality systems, are provided below, with specific NIST guidance indicated in bold print. 


\subsection{Requirements for Registrars (From Subpart L of the Regulations)}

\section{General}

$\mathrm{Sec}$.

280.1100 Introduction.

280.1101 Scope.

\section{Requirements for Registrars}

280.1110 Registrars.

280.1111 Registrar personnel.

280.1112 Changes in the registration requirements.

280.1113 Appeals, complaints and disputes.

\section{Requirements for Registration}

280.1120 Application for registration.

280.1121 Preparation for assessment.

280.1122 Assessment.

280.1123 Assessment report.

280.1124 Decision on registration.

280.1125 Surveillance and reassessment procedures.

280.1126 Use of certificates and logos.

280.1127 Access to records of complaints to fastener manufacturers.

\section{General}

Sec. 280.1100 Introduction.

This subpart sets out organizational, operational and other requirements that must be met by all Registrars accredited under Subparts I or J of this part.

Sec. 280.1101 Scope.

These are general requirements that must be met by a third-party body registering Facilities. Note: In some countries, the bodies which verify conformity of quality systems to specified standards are called "certification bodies," in others "registration bodies," in others "assessment and registration bodies" or "certification/registration bodies," and in still others "registrars." Reference to such bodies as "Registrars" should not be understood to be limiting. 


\section{Requirements for Registrars}

Sec. 280.1110 Registrars.

(a) General provisions.

(1) The policies and procedures under which the Registrar operates shall be nondiscriminatory, and they shall be administered in a non-discriminatory manner. Procedures shall not be used to impede or inhibit access by applicants other than as specified in this part ${ }^{l}$.

(2) The Registrar shall make its services accessible to all applicants. There shall not be undue financial or other conditions. Access shall not be conditional upon the size of the applicant body or membership of any association or group, nor shall registration be conditional upon the number of Facilities already registered.

(3) The criteria against which the quality assurance system of an applicant is assessed shall be those outlined in the quality system standards or other normative documents relevant to the function performed. If an explanation is required as to the application of these documents to a specific registration program, it shall be formulated by relevant and impartial committees or persons possessing the necessary technical competence, and published by the Registrar.

Registrars shall audit applicant and Registered Facilities using the criteria contained in NISTIR 6263 Requirements for Fastener Facilities Registering a Quality Assurance System Under Provisions of the Fastener Quality Act.

The registration process shall include the specific requirements for fastener facilities in the regulations including a quality assurance system standard which meets the various quality system requirements. NIST has determined that QS-9000 Quality System Requirements meets these requirements. If a Facility requests registration to a standard other than QS-9000, the Registrar must make a determination that the other standard uses a set of requirements equivalent to QS-9000. The Registrar, once satisfied as to equivalence, must submit to NIST a request with supporting documentation for acceptance of the other standard. Supporting documentation shall include a cross-reference comparison of requirements between QS-9000 and the other standard. Based on an evaluation of the submission, NIST will make a determination if the proposed standard meets the QAS requirements. The Registrar and its Accreditor will be notified of NIST's decision.

(4) The Registrar shall confine its requirements, assessment, and decision on registration to those matters specifically related to the scope of the registration being considered.

\footnotetext{
${ }^{1}$ Use of the term "part" in the regulations refers to 15 CFR Part 280 "Procedures for Implementation of the Fastener Quality Act."
} 
(b) Organization of a Registrar. The structure of the Registrar shall be such as to give confidence in its registrations. In particular, the Registrar shall:

(1) Be impartial;

(2) Be responsible for its decisions relating to the granting, maintaining, extending, reducing, suspending and withdrawing of registration;

(3) Identify the management (committee, group, or person) which will have overall responsibility for each of the following:

(i) Performance of assessment and registration as defined in this part;

(ii) Formulation of policy matters relating to the operation of the Registrar;

(iii) Decisions on registration;

(iv) Supervision of the implementation of its policies;

(v) Supervision of the finances of the Registrar; and

(vi) Delegation of authority to committees or individuals, as required, to undertake defined activities on its behalf.

(4) Have documents which demonstrate that it is a legal entity;

(5) Have a documented structure which safeguards impartiality, including provisions to assure the impartiality of the operations of the Registrar. This structure shall enable the participation of all parties significantly concerned in the development of policies and principles regarding the content and functioning of the registration system;

(6) Ensure that each decision on registration is taken by a person or persons different from those who carried out the assessment;

(7) Have rights and responsibilities relevant to its registration activities;

(8) Have adequate arrangements to cover liabilities arising from its operations and/or activities;

(9) Have the financial stability and resources required for the operation of a registration system;

(10) Employ a sufficient number of personnel having the necessary education, training, technical knowledge, and experience for performing registration functions relating to the type, range, and volume of work performed, under a responsible senior executive; 
The senior executive shall have sufficient experience and demonstrated ability in the successful operation of a registration program operating on a national or international scale.

The executive shall have appropriate experience/education in management principles/application, technical knowledge of quality system application in manufacturing facilities, and personnel management.

At least one staff member shall have technical expertise in engineering, physics, metallurgy, or other technical field which provides enough technical background to understand the technology involved in the production and testing of fasteners.

(11) Have a quality system, as outlined in Sec. 280.1110(d), giving confidence in its ability to operate a registration system for Facilities;

(12) Have policies and procedures that distinguish between registration and any other activities in which the Registrar is engaged;

The Registrars shall have policies which:

prevent registration from being misrepresented as product certification;

ensure that Registered Facilities do not imply product certification, approval or endorsement by NIST or any other agency of the Federal government as a result of being registered;

(13) Together with its senior executive and staff, be free from any commercial, financial, and other pressures which might influence the results of the registration process;

(14) Have formal rules and structures for the appointment and operation of any committees which are involved in the registration process; such committees shall be free from any commercial, financial, and other pressure that might influence decisions;

(15) Ensure that activities of related bodies do not affect the confidentiality, objectivity, or impartiality of its registrations and shall not offer or provide, directly or indirectly, those services that it registers others to perform, consulting services to obtain or maintain registration, or services to design, implement, or maintain quality systems;

(16) Have policies and procedures for the resolution of complaints, appeals, and disputes received from fastener manufacturers or other parties about the handling of registration or any other related matters;

(17) Have a structure where members are chosen to provide a balance of interests, where no single interest predominates; and 


\section{The Registrar shall have access to appropriate experts, professional services or other resources needed to assure adequate technical support, advice and assistance.}

(18) Assure that other products, processes, or services that may be offered, directly or indirectly, do not compromise confidentiality or the objectivity or impartiality of its registration process and decisions.

\section{(c) Subcontracting.}

(1) When a Registrar decides to subcontract work related to registration (e.g. audits) to an external body or person, a properly documented agreement covering the arrangements, including confidentiality and conflicts of interest, shall be drawn up. The Registrar shall include procedures for subcontracting in its quality documentation, shall only subcontract work to another accredited NIST listed Registrar, and shall.

(i) Take full responsibility for such subcontracted work and maintain its responsibility for granting, maintaining, extending, reducing, suspending, or withdrawing registration;

(ii) Ensure that the subcontracted body or person is competent and complies with the applicable provisions of this part, including section 280.7, and is not involved, either directly or through its employer, with the design, implementation, or maintenance of a quality system in such a way that impartiality could be compromised; and

(iii) Obtain the consent of the applicant or fastener manufacturer whose Facility is registered, before the fact; and clearly indicate in all appropriate records and reports to the client specifically what functions were subcontracted.

(2) Requirements in paragraphs (c)(1) and (2) of this section are also relevant, by extension, when a Registrar uses, for granting its own registration, work provided by another Registrar with which it has signed an agreement.

\section{(d) Quality system.}

(1) The management of the Registrar with executive responsibility for quality shall define and document its policy for quality, including objectives for quality and its commitment to quality. The management shall ensure that this policy is understood, implemented, and maintained at all levels of the organization.

(2) The Registrar shall operate a quality system in accordance with the relevant elements of this part and appropriate to the type, range, and volume of work performed. This quality system shall be documented and the documentation shall be available for use by the staff of the Registrar. 
(3) The Registrar shall ensure effective implementation of the documented quality system procedures and instructions.

(4) The Registrar shall designate a person with direct access to its highest executive level who, irrespective of other responsibilities, shall have defined authority to ensure that a quality system is established, implemented, and maintained in accordance with this part, and report on the performance of the quality system to the management of the Registrar for review and as a basis for improvement of the quality system.

(5) The quality system shall be documented in a quality manual and associated quality procedures.

The quality documentation shall contain current, complete, and detailed information describing the Registrar and the internal organizational structure and quality system used to control the quality of all registration activities. The documentation should contain policies, procedures and methods to cover all aspects of the operation to ensure that the managerial, technical, administrative and human factor elements which might affect the quality of services are under control. Guidance in developing or operating a quality system can be found in the References and the quality manual shall contain or refer to at least the following:

(i) A quality policy statement;

including quality objectives

(ii) A brief description of the legal status of the Registrar, including the names of its owners, if applicable, and, if different, the names of the persons who control it;

(iii) The names and qualifications, experience, and terms of reference of the senior executive and other certification/registration personnel, affecting the quality of the certification/registration function;

(iv) An organization chart showing lines of authority, responsibility, and allocation of functions stemming from the senior executive and, in particular, the relationship between those responsible for the assessment and those taking decisions regarding registration;

(v) A description of the organization of the registration body, including details of the management (committee, group, or person), its constitution, terms of reference and rules of procedure;

The following shall be included:

primary functions of key personnel; 
technical resources, including facilities, equipment;

the function and location of each unit which is involved in registration activities for fastener Facilities; and

\section{scope of operation of the Registrar;}

(vi) The policy and procedures for conducting management reviews;

(vii) Administrative procedures including document control;

(viii) The operational and functional duties and services pertaining to quality, so that the extent and limits of each person's responsibility are known to all concerned;

(ix) The policy and procedures for the recruitment and training of registration body personnel (including auditors) and monitoring their performance;

(x) A list of its subcontractors and details of the procedure for assessing, recording, and monitoring their competence;

(xi) Its procedures for handling nonconformities and for assuring the effectiveness of any corrective actions taken;

(xii) The policy and procedures for implementing the registration process, including:

(A) The conditions for issue, retention, and withdrawal of registration documents;

(B) Checks of the use and application of documents used in the registration of quality systems;

(C) The procedures for assessing and registering fastener manufacturers' quality systems as employed in particular Facilities; and

(D) The procedures for surveillance and reassessment of Registered Facilities.

Policies and procedures shall be included to describe how the Registrar:

adjudicates all matters relating to its operation;

reviews policies;

reviews finances;

conducts staff training; 
creates committees as required;

provides for and responds to comment by affected entities;

controls the ownership, use and display of the registration documents, and the manner in which a Registered Facility may refer to its accreditation status;

maintains control over information collection and handling, e.g., Facility status, scheduling of renewals, on-site assessments, assessor assignments, etc.;

determines applicant eligibility;

conducts on-site assessment, including criteria for assessment, checklists, report forms and requirements;

makes decisions on registration actions, e.g., registration, renewal, revocation, suspension, denial, termination;

allows Registered Facilities to refer to their registered status on documents;

handles complaints, e.g., from applicant and Registered Facilities, Facility clients, regulatory agencies, etc.;

controls Registered Facility subcontracting services;

provides surveillance of Registered Facilities;

controls information dissemination, including confidentiality requirements, e.g., directory, electronic media, publicity, phone calls;

permits the prompt notification to NIST and other interested parties of any change in the status of a Registered Facility;

maintains and retains records, and

reviews and updates the quality system.

(xiii) The policy and procedures for dealing with appeals, complaints, and disputes; and

(xiv) The procedures for conducting internal audits based on the provisions described in appropriate international documentation. 
(e) Conditions for granting, maintaining, extending, reducing, suspending, and withdrawing registration.

(1) The Registrar shall specify the conditions for granting, maintaining, reducing, and extending registration and the conditions under which registration may be suspended or withdrawn, partially or in total, for all or part of the Facility's scope of registration. In particular, the Registrar shall require the fastener manufacturer to notify it promptly of any intended changes to the quality assurance system or other changes which may affect conformity.

(2) The Registrar shall require the fastener manufacturer to have a documented quality system which conforms to applicable quality system standards or other normative documents.

(3) The Registrar shall have procedures to grant, maintain, withdraw and, if applicable, suspend registration; to extend or reduce the scope of registration; and to conduct reassessment in the event of changes significantly affecting the activity and operation of the Facility (such as change of ownership, changes in personnel or equipment), or if analysis of a complaint or any other information indicates that the Registered fastener Facility no longer complies with the requirements of the Registrar.

(4) The Registrar shall have documented procedures which shall be made available on request for:

(i) Initial assessment and for the surveillance and reassessment of a fastener manufacturer's quality assurance system as employed in a particular Facility

(ii) Continuing conformity with relevant requirements; and for verifying and recording that a fastener manufacturer takes corrective action on a timely basis to correct all nonconformities; and

(iii) Identifying and recording nonconformities and the need for corrective action by fastener manufacturers on a timely basis for such items as incorrect references to the registration or misleading use of registration information.

\section{(f) Internal audits and management reviews.}

(1) The Registrar shall conduct periodic internal audits covering all procedures in a planned and systematic manner, to verify that the quality assurance system is implemented and is effective. The Registrar shall ensure that personnel responsible for the area audited are informed of the outcome of the audit; corrective action is taken in a timely and appropriate manner; and the results of the audit are recorded.

The quality system shall be reviewed at least annually. 
(2) The top management of the Registrar shall review its quality system at defined intervals sufficient to ensure its continuing suitability and effectiveness in satisfying the requirements of this part and the stated quality policy and objectives. Records of such reviews shall be maintained.

\section{(g) Documentation.}

(1) The Registrar shall document, update at regular intervals, and make available through publications, electronic media, or other means, on request

(i) Information about the authority under which the Registrar operates;

(ii) A documented statement of its registration system including its rules and procedures for granting, maintaining, extending, reducing, suspending, and withdrawing registration;

(iii) Information about the assessment and registration process;

(iv) A description of the means by which the Registrar obtains financial support, and general information on the fees charged to applicants and fastener manufacturers whose Facilities have been registered;

(v) A description of the rights and duties of applicants and fastener manufacturers whose Facilities have been registered, including requirements, restrictions, or limitations on the use of the Registrar's logo and on the ways of referring to the registration granted;

The Registrar shall make available to its accreditor:

the registration criteria (requirements) that applicant Facilities must satisfy in order to be granted registration;

copies of program handbooks, or other explanatory documents; and

examples of all forms used, e.g., applications for accreditation, control forms, and data sheets, assessment checklists, report forms, etc.;

(vi) Information on procedures for handling complaints, appeals and disputes; and

(vii) A directory of Registered Facilities, including their locations, describing the scope of registration granted to each.

(2) The Registrar shall establish and maintain procedures to control all documents and data that relate to its registration functions. These documents shall be reviewed and approved for adequacy by appropriately authorized and competent personnel prior to 
issuing any documents following initial development or any subsequent amendment or change being made. A listing of all appropriate documents with the respective issue and/or amendment status identified shall be maintained. The distribution of all such documents shall be controlled to ensure that the appropriate documentation is made available to personnel of the Registrar or of the fastener manufacturer whose Facility is registered, when required to perform any function relating to the activities of an applicant or registered Facility.

(h) Records.

(1) The Registrar shall maintain a record system to suit its particular circumstances and to comply with this part. The records shall demonstrate that the registration procedures have been effectively fulfilled, particularly with respect to application forms, assessment reports, and other documents relating to granting, maintaining, extending, reducing, suspending, or withdrawing registration. The records shall be identified, managed and disposed of in such a way as to ensure the integrity of the process and confidentiality of the information. The records shall be kept for a period of five years.

(2) The Registrar shall have a policy and procedures for retaining records for a period of five years. The Registrar shall have a policy and procedures concerning access to these records consistent with paragraph (h) (1) of this section.

\section{The Registrar shall meet the requirements of Sec 280.808 and Sec 280.809 .}

\section{(i) Confidentiality.}

(1) The Registrar shall have adequate arrangements, consistent with applicable laws to safeguard confidentiality of the information obtained in the course of its registration activities at all levels of its organization, including committees and external bodies or individuals, acting on its behalf.

(2) Except as required in this part, information about a particular product, quality assurance system, Facility, or fastener manufacturer shall not be disclosed to a third party without the written consent of the fastener manufacturer.

Sec. 280.1111 Registrar personnel.

(a) General provisions.

(1) The personnel of the Registrar involved in registration shall be competent for the functions they perform.

(2) Information on the relevant qualifications, training and experience of each member of the personnel involved in the registration process shall be maintained by the Registrar. Records of training and experience shall be kept up to date. 
(3) Clearly documented instructions shall be available to the personnel describing their duties and responsibilities. These instructions shall be maintained up to date.

(b) Qualification criteria for auditors and technical experts.

(1) In order to ensure that assessments are carried out effectively and uniformly, the minimum relevant criteria for competence shall be defined by the Registrar.

(2) Auditors shall meet the requirements of the appropriate international documentation. For the assessment of a quality system, the relevant guidelines for auditing and the criteria for auditors are those defined in the appropriate international documentation.

(3) Technical experts are not required to comply with the requirements for auditors, and guidance on their personal attributes may be obtained the appropriate international documentation.

(c) Selection procedure.

(1) The Registrar shall have a procedure for selecting auditors and, if applicable, technical experts on the basis of their competence, training, qualifications, and experience, and for initially assessing the conduct of auditors and technical experts during assessment and subsequently monitoring the performance of auditors and technical experts.

The Registrar shall have documented selection criteria that each potential auditor must meet. The criteria shall contain requirements for education, technical, quality systems, management, and communication skills, with a specified minimum number of years of applicable experience for each category.

(2) When selecting the audit team to be appointed for a specific assessment, the Registrar shall ensure that the skills brought to each assignment are appropriate. The team shall:

(i) Be familiar with the Fastener Quality Act and its implementing regulations, registration procedures and registration requirements;

(ii) Have a thorough knowledge of the relevant assessment method and assessment documents;

(iii) Have appropriate technical knowledge of the fastener technology for which registration is sought and where relevant with associated procedures and their potential for failure (technical experts who are not auditors may fulfill this function); 
(iv) Have a degree of understanding sufficient to make a reliable assessment of the competence of the Facility to provide products, processes or services in its registered scope;

\section{One or more team member(s) shall be capable of assessing the Facility's implementation of advanced product quality planning and use of control plans.}

(v) Be able to communicate effectively, both in writing and orally, in the required languages;

(vi) Be free from any interest that might cause team members to act in other than an impartial or non-discriminatory manner, for example:

(A) Audit team members or their organization shall not have provided consulting services to the applicant or fastener manufacturer whose Facility is registered which compromise the registration process and decision; and

(B) In accordance with the directives of the Registrar, the audit team members shall inform the Registrar, prior to the assessment, about any existing, former or envisaged link between themselves or their organization and the fastener manufacturer whose Facility is to be assessed.

(d) Contracting of assessment personnel. The Registrar shall require the personnel involved in the assessment to sign a contract or other document by which they commit themselves to comply with the rules defined by the Registrar, including those relating to confidentiality and those relating to independence from commercial and other interests, and any prior and/or present link with the fastener manufacturers whose Facilities are to be assessed. The Registrar shall ensure that, and document how, any subcontracted assessment personnel satisfy all the requirements for assessment personnel outlined in this subpart.

(e) Assessment personnel records.

(1) The Registrar shall possess and maintain up-to-date records on assessment personnel, consisting of:

(i) Name and address;

(ii) Affiliation and position held in the organization,

(iii) Educational qualifications and professional status;

(iv) Experience and training in each field of competence of the Registrar;

(v) Date of most recent updating of records; and 
(2) The Registrar shall ensure and verify that any subcontracted body maintains records which satisfy the requirements of this part, of assessment personnel who are subcontracted to the Registrar.

(f) Procedures for audit teams. Audit teams shall be provided with up-to-date assessment instructions and all relevant information on registration arrangements and procedures.

\section{Sec. 280.1112 Changes in the registration requirements.}

The Registrar shall give due notice of any changes it intends to make in its requirements for registration. It shall take account of views expressed by the interested parties before deciding on the precise form and effective date of the changes. Following a decision on, and publication of, the changed requirements, it shall verify that each fastener manufacturer whose Facility is registered carries out any necessary adjustments to its procedures within such time as, in the opinion of the Registrar, is reasonable.

\section{Sec. 280.1113 Appeals, complaints and disputes.}

Appeals, complaints and disputes brought before the Registrar by fastener manufacturers or other parties shall be subject to the procedures of the Registrar. The Registrar shall keep a record of all appeals, complaints and disputes, and remedial actions relative to registration; take appropriate corrective and preventive action; and document the actions taken and assess their effectiveness.

\section{Requirements for Registration}

\section{Sec. 280.1120 Application for registration.}

(a)(1) The Registrar shall maintain up-to-date, as specified in Sec. 280.1110(g)(1), detailed descriptions of the assessment and registration procedure, the documents containing the requirements for registration and documents describing the rights and duties of fastener manufacturers whose Facilities are registered, and shall provide them to applicants and those fastener manufacturers. The Registrar shall require that a fastener manufacturer whose Facility is registered:

(i) Always complies with the relevant provisions of this part;

\section{Registrars shall audit applicant and Registered Facilities using the requirements in NISTIR 6263 Quality Assurance System Registration Requirements for Facilities Under the Fastener Quality Act.}

(ii) Makes all necessary arrangements for the conduct of the assessment, including provision for examining documentation and the access to all areas, records 
(including internal audit reports) and personnel for the purposes of assessment, surveillance, reassessment, and resolution of complaints;

(iii) Only claims that its Facility is registered with respect to those activities for which it has been granted registration;

(iv) Does not use the registration in such a manner as to bring the Registrar into disrepute, and does not make any statement regarding its registration which the Registrar may consider misleading or unauthorized;

(v) Upon suspension or withdrawal of the registration (however determined), discontinues use of all advertising matter that contains any reference thereto and returns any registration documents as required by the Registrar;

(vi) Uses registration only to indicate that the quality assurance system as employed in its Registered Facility is in conformity with specified standards or other normative documents, and does not use the registration to imply that a product or service is approved by the Registrar, as required by section 280.804;

Neither a Registrar accredited under the Act, nor any registered Facility shall take any action which constitutes or implies certification, approval, or endorsement by NIST or any other agency of the U.S. government of fasteners entered into commerce in the United States.

Neither an Accredited Registrar, nor any Registered Facility shall take any action which constitutes or implies that the Registrar, or Facility is recognized by NIST for any activities beyond those which are specifically stated in the NIST recognition documents.

(vii) Ensures that no registration document, mark or report, or any part thereof, is used in a misleading manner; and

(viii) In making reference to the registration in communication media such as documents, brochures, or advertising, complies with the requirements of the Registrar.

(2) When the desired scope of registration is related to a specific program, any necessary explanation shall be provided to the fastener manufacturer. If requested, additional application information shall be provided to the fastener manufacturer.

(b) The Registrar shall require an official application form, duly completed and signed by a duly authorized representative of the applicant fastener manufacturer in which or attached to which:

(1) The scope of the desired registration is defined; and 
(2) The applicant agrees to comply with the requirements for registration and to supply any information needed for its evaluation, including the requirements of the Act and regulation.

(c)(1) At least the following information shall be provided by the applicant prior to the on-site assessment:

(i) The general features of the applicant, such as corporate entity, name, addresses, legal status and, where relevant, human and technical resources;

(ii) General information concerning the quality system and the activities it covers;

(iii) A description of the systems to be registered and the standards or other normative documents applicable to each; and

(iv) A copy of its quality manual and, where required, the associated documentation.

(2) The information gathered from the application documentation and the quality manual review may be used for the preparation of the on-site assessment and shall be treated with appropriate confidentiality.

Sec. 280.1121 Preparation for assessment.

(a) Before proceeding with the assessment the Registrar shall conduct, and maintain records of, a review of the request for registration to ensure that:

(1) The requirements for registration are clearly defined, documented, and understood;

(2) Any difference in understanding between the Registrar and the applicant is resolved; and

(3) The Registrar has the capability to perform the registration service with respect to the scope of the registration sought, the location of the applicant's operations, and any special requirements such as the language used by the applicant.

(b) The Registrar shall prepare a plan for its assessment activities to allow for the necessary arrangements to be made.

See QS-9000 Quality System Requirements, 3rd Ed, Appendix H for guidance on audit-day requirements as a function of the number of Facility employees.

(c) The Registrar shall nominate a qualified audit team to evaluate all material collected from the applicant and to conduct the audit on its behalf. Experts in the areas to be assessed may be attached to the Registrar's team as advisers. 
(d) The fastener manufacturer shall be informed of the names of the members of the audit team who will carry out the assessment, with sufficient notice to appeal against the appointment of any particular auditors or experts.

(e) The audit team shall be formally appointed and provided with the appropriate working documents. The plan for and the date of the audit shall be agreed to by the fastener manufacturer. The mandate given to the audit team shall be clearly defined and made known to the fastener manufacturer, and shall require the audit team to examine the structure, policies, and procedures of the Facility and the quality assurance system it employs, and confirm that these meet all the requirements relevant to the scope of registration, and that the procedures are implemented and are such as to give confidence in the products, processes, or services of the Facility being evaluated.

Audit checklists shall be developed to include: FQA specific requirements, quality system requirements (e.g., QS-9000 Quality System Requirements, 3rd Ed) and control plan requirements to include all applicable elements found in QS-9000 Advanced Product Quality Planning and Control Reference Manual, Supplement D, Control Plan for Tooling Dominant Process, pg. 51, June 1994.

Sec. 280.1122_Assessment.

The audit team shall assess the quality assurance system, employed in the Facility being evaluated, covered by the defined scope against all applicable registration requirements.

Sec. 280.1123 Assessment report.

(a) The Registrar may adopt reporting procedures that suit its needs but, as a minimum, these procedures shall ensure that:

(1) A meeting takes place between the audit team and the fastener manufacturer's management prior to leaving the premises, at which the audit team provides a written or oral indication regarding the conformity of the quality assurance system, as employed in particular Facility, with the particular registration requirements and provides an opportunity for the fastener manufacturer to ask questions about the findings and their basis;

(2) The audit team provides the Registrar with a report of its findings as to the conformity of the quality assurance system, as employed in the particular Facility, with all of the registration requirements;

(3) A report on the outcome of the assessment is promptly brought to the fastener manufacturer's attention by the Registrar, identifying any nonconformity to be discharged in order to comply with all of the registration requirements;

(4) The Registrar shall invite the fastener manufacturer to comment on the report and to describe the specific actions taken, or planned to be taken within a defined time, to remedy 
any nonconformity with the registration requirements identified during the assessment of its quality assurance system, as employed in the particular Facility, and shall inform the fastener manufacturer of the need for full or partial reassessment of its quality assurance system or whether a written declaration to be confirmed during surveillance will be considered adequate;

(5) The report shall contain as a minimum:

(i) The date(s) of the audit(s);

(ii) The name(s) of the person(s) responsible for the report;

(iii) The names and addresses of the Facility audited;

(iv) The assessed scope of registration or reference thereto, including reference to the standard(s) applied;

(v) Comments on the conformity of the quality assurance system, as employed in the particular Facility, with the registration requirements, with a clear statement of nonconformity and, where applicable, any useful comparison with the results of previous assessments of the quality assurance system, as employed in that particular Facility; and

(vi) An explanation of any differences from the information presented to the body at the closing meeting.

(b) If the final report authorized by the Registrar differs from the report referred to in paragraphs (a)(3) and (5) of this section, it shall be submitted to the fastener manufacturer with an explanation of any differences from the previous report. The report shall take into consideration:

(1) The qualification, experience, and authority of the staff encountered;

(2) The adequacy of the internal organization and procedures adopted by the applicant body to give confidence in the quality assurance system, as employed in the particular Facility; and

(3) The actions taken to correct identified nonconformities including, where applicable, those identified at previous assessments.

Sec. 280.1124 Decision on registration.

(a) The decision whether or not to register a fastener Facility shall be taken by the Registrar on the basis of the information gathered during the registration process and any other relevant information. Those who make the registration decision shall not have participated in the audit. 
(b) The Registrar shall not delegate authority for granting, maintaining, extending, reducing, suspending, or withdrawing registration to an outside person or body.

(c) The Registrar shall provide to each fastener manufacturer whose Facility is registered, registration documents such as a letter or a certificate signed by an officer who has been assigned such responsibility. These documents shall identify, for the fastener manufacturer and the particular Facility covered by the registration:

(1) The name and addresses;

(2) The scope of registration granted, including as appropriate:

(i) The quality system standards and/or other normative documents to which quality systems are registered;

(ii) The product, process, or service categories; and, if appropriate,

(iii) Regulatory requirements, product standards, or other normative documents against which products are supplied.

(3) The effective date of registration and the term for which the registration is valid.

(4) A statement that the Registered Facility meets the requirements of the Fastener Quality Act and Regulations as detailed in Title 15, Part 280, Code of Federal Regulations.

(d) Any application for amendment to the scope of a previously granted registration shall be processed by the Registrar. The Registrar shall decide what, if any, assessment procedure is appropriate to determine whether or not the amendment should be granted and shall act accordingly.

Sec. 280.1125 Surveillance and reassessment procedures.

(a) The Registrar shall carry out periodic surveillance and reassessment at sufficiently close intervals to verify that its Registered Facilities continue to comply with the registration requirements. The period involved cannot be greater than one year.

Each on-site audit shall include a review of customer complaints and response, and internal audit and management review results and actions.

(b) Surveillance and reassessment procedures shall be consistent with those concerning the assessment of the Registered Facility as described in this part.

The entire quality system shall be assessed at least once every three years. Each Registered Facility's design and manufacturing location shall be audited and referenced on the certificate of registration. It is acceptable for each surveillance audit to re-examine part of 
the system such that a complete reassessment is completed during each three year cycle. Also, each location shall receive a surveillance audit at a minimum of once in every consecutive twelve month period. The final surveillance audit in each three year period may or may not involve a complete system assessment. The surveillance audit report shall document findings and indicate the part of the system that was audited.

Sec. 280.1126 Use of certificates and logos.

(a) The Registrar shall exercise proper control over ownership, use and display of its quality system registration mark and logos.

(b) If the Registrar confers the right to use a symbol or logo to indicate registration of a Facility, the fastener manufacturer may use the specified symbol or logo only as authorized in writing by the Registrar. This symbol or logo shall not be used on a product or in a way that may be interpreted as denoting product conformity.

(c) The Registrar shall take suitable action to deal with incorrect references to the registration system or misleading use of certificates and logos found in advertisements, catalogs, etc. Such action could include corrective action, withdrawal of certificate, publication of the transgression and, if necessary, other legal action.

Sec. 280.1127 Access to records of complaints to fastener manufacturers.

The Registrar shall require each fastener manufacturer whose Facility is registered to make available to the Registrar, when requested, the records of all complaints and corrective action taken in accordance with the requirements of the quality system standards or other normative documents.

\subsection{FACILITY REQUIREMENTS}

Facility requirements for registration are contained in 15 CFR Part 280 Sec. 280.104, subpart I and NISTIR 6263 Quality Assurance System Registration Requirements for Facilities Under the Fastener Quality Act. 


\section{BIBLIOGRAPHY}

The Fastener Quality Act (Pub. L. 101-592, as amended by Pub. L. 104-113).

Procedures for Implementation of the Fastener Quality Act; 15 CFR Part 280.

ISO/IEC Guide 2:1996, Standardization and related activities-General vocabulary.

ISO/IEC Guide 61:1996, General requirements for assessment and accreditation of certification/registration bodies.

ISO/IEC Guide 62:1996, General requirements for bodies operating assessment and certification/registration of quality systems.

ISO 8402:1994, Quality management and quality assurance-Vocabulary.

ISO 9001:1994, Quality systems-Model for quality assurance in design, development, production, installation, and servicing.

ISO 9002:1994, Quality systems-Model for quality assurance in production, installation, and servicing.

ISO 10011-1:1990, Guidelines for auditing quality systems-Part 1: Auditing.

ISO 10011-2:1991, Guidelines for auditing quality systems—Part 2: Qualification criteria for quality systems auditors.

ISO 10011-3:1991, Guidelines for auditing quality systems-Part 3: Management of audit programmes.

ISO 10013:1995, Guidelines for developing quality manuals.

QS-9000, Quality System Requirements, Third edition, March 1998, Chrysler Corporation, Ford Motor Company, General Motors Corporation-Automotive Industry Action Group.

Advanced Product Quality Planning (APQP) and Control Plan Reference Manual, June 1994, Chrysler Corporation, Ford Motor Company, General Motors Corporation-Automotive Industry Action Group.

Statistical Process Control (SPC) Reference Manual, 1992, Chrysler Corporation, Ford Motor Company, General Motors Corporation-Automotive Industry Action Group. 
Stiefel, S. Wayne and Gladhill, Robert L., Procedures for Obtaining NIST Recognition as an Accreditor of Quality System Registrars Under the Fastener Quality Act, NISTIR 6161, December 1998.

Stiefel, S. Wayne and Gladhill, Robert L., Quality Assurance System Registration Requirements for Facilities Under Provisions of the Fastener Quality Act, NISTIR 6263, December 1998. 

